\title{
Can endoscopy and laparoscopy be combined to remove complex polyps?
}

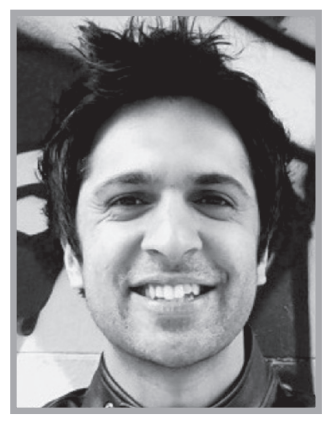

Sam Sharma'

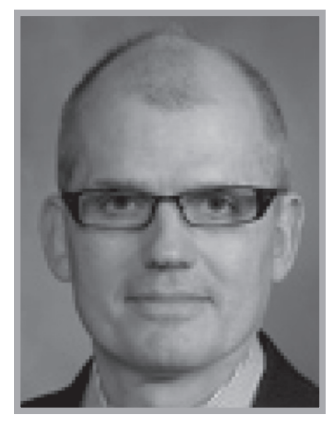

Jeffrey W Milsom

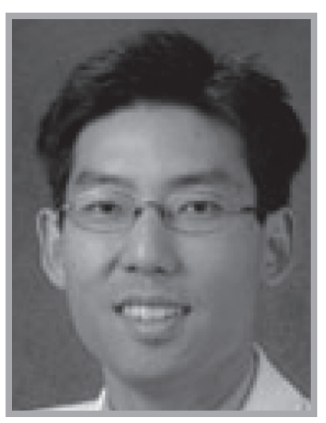

James Yoo*2
The adenoma-carcinoma sequence describes a well-established progression from normal mucosa to dysplastic epithelium leading to invasive cancer. Any polyp left untreated has the potential to become a cancer. The diagnostic and therapeutic capability of endoscopy has been proven recently in a large study demonstrating a 53\% reduction in mortality in patients undergoing regular colonoscopy [1]. The number of individuals set to undergo screening for polyps is to increase with programs incepted worldwide. As specialists in the field, we will see more and do more in the coming years.

A certain percentage of polyps encountered by the clinician will be termed 'complex' or 'complicated' and are therefore not amenable to simple removal techniques. Such polyps require additional intervention in light of the adenoma-carcinoma sequence and the fact that at least $15 \%$ of polyps that are not removable endoscopically actually harbor cancer. Advanced techniques for removal can be classed as luminal (endoscopic mucosal resection [EMR]/endoscopic submucosal dissection [ESD]) or segmental full-thickness resection through surgery. Surgical resection with its inherent risks is often performed, although we understand that over $80 \%$ of these patients will have a benign lesion. More recently, combined endoscopic laparoscopic surgery (CELS), a new combined approach to tackling complex polyps has evolved. This article attempts to consolidate the available literature regarding the feasibility of this technique, in addition to providing guidance on how teams may embark on such a treatment.

\section{Evolution of the technique (EMR, ESD to CELS)}

The use of combined laparoscopic and endoscopic techniques has been employed for some time now, with the first report on sequential combined endoscopic and laparoscopic procedures for biliary choledocholithiasis described in 1994 [2]. 


\footnotetext{
"Any polyp left untreated has the potential to become a cancer."
}

Karanfilian et al. then reported resection of a gastric vascular malformation through a CELS approach [3]. In 2003, Walsh et al. published a series of 14 gastric stromal tumor resections utilizing the CELS technique [4]. The evolution of lesion treatment began within the gastric field and with the tools in place, specialists transferred their skills from upper to lower intestinal disease; however, the use of this technique within the colorectal field is one of relative novelty.

Simple snare polypectomy was unsuitable for complex polyps, so EMR was developed. The key differentiating step in the procedure was the use of a submucosal injection (an injection of various components in solution). This injection provided a cushion, allowing piecemeal band or snare ligation with or without suction into an endoscopic cap (placed on the endoscope tip). However, piecemeal removal is imprecise and the adequacy of resection margins is important in the context of neoplastic disease. Presently, EMR has been used for lesions up to T1 (sm1) with a failure rate quoted as up to $10 \%$ [5]. The en-bloc resection rate is quoted as circa $58 \%$, recurrence rate $14 \%$ and a perforation rate of $1.3 \%[5,6]$. Average procedural time is quoted as $29 \mathrm{~min}[7]$.

ESD developed from EMR, respresenting a logical progression that attempted to ameliorate the imprecise nature of piecemeal resection through endoscopic dissection in the submucosal plane [8]. Specialist instruments were developed that transferred cautery energy through the working channel of the endoscope. Again, using a cap and submucosal injection, burns/marks are made around the lesion for demarcation purposes. From this, the submucosal plane is entered and using the cap as a retractor, submucosal fibers are divided. Piecemeal resection is obviated, providing larger surface area removal. If we compare ESD with EMR, the en-bloc resection rate is quoted as $84 \%$ and the recurrence rate $2 \%[9]$. However, in expert hands the ESD technique gives a perforation rate of $6.2 \%$ with an average procedural time of $108 \mathrm{~min}$ [10]. These figures provide a key insight into why uptake in the western world has been slow.

\section{Combined approach}

From the inception of laparoscopic cholecystectomy, laparoscopic-assisted procedures have become ubiquitous. The limitations of ESD have the potential to be eased through the help of an extramural assistant. External manipulation of the bowel presents the lesion in a favorable fashion to the endoscopic operator. The expected outcome is one of reduced operating time and lower risk of perforation. If a perforation does occur, rapid diagnosis can be made through direct observation and sutures placed.

\section{- Patient/polyp selection}

Anesthetic safety as well as the suitability for an abdominal procedure should be assessed. Patients need to be counseled and consented for the possible need for a repeat procedure, pending histology. Potential risks and benefits should also be discussed.

The definition of a complex or difficult polyp is an individual one. Owing to this lack of consensus, arbitrary categories have been proposed. These include (but by no means are exhaustive) a polyp greater than $3 \mathrm{~cm}$, a broad base, crossing two or more haustral folds and other difficult locations. Intrinsically, the colon with its folds and tortuosity can provide some of the most difficult locations and landscapes of the GI tract.

\section{- Technique}

Laparoscopic instruments are used to manipulate and compress the bowel favorably presenting the lesion to the endoscopic operator. Two operators are therefore needed, capable in each technique. $\mathrm{CO}_{2}$ insufflation is used both endoscopically and laparoscopically. Nakajima et al. have published an article about the endoscopic benefits of $\mathrm{CO}_{2}$, primarily attributed to the rapid rate of absorption compared with room air $(150 \times$ faster) $[10,11]$. Briefly, our technique is as follows. The patient is first prepared, draped and placed in lithotomy and a screening colonoscopy is performed to identify and mark the lesion as necessary. Once the lesion is identified and assessed (through ancillary techniques such as narrow-band imaging), an umbilical port is placed using the open technique and pneumoperitoneum is established. Next, the position of the lesion is reconfirmed endoscopically and laparoscopically, at which point, further ports are placed according to lesion location and operator preference. In some cases adhesiolysis or mobilization will need to be performed for lateral or retroperitoneal lesions. Once the lesion position has been identified, the base is presented favorably to the endoscopic operator by the laparoscopic operator. At this point, the method of endoscopic removal of the lesion is a personal one. Whether it be through simple snare, EMR or ESD, the choice will depend on the morphology of the lesion (further information on the CELS technique can be found in [12]). 


\section{- Literature review of existing data}

To date a number of papers have published outcomes following colonic CELS procedures. A direct randomized comparative study between CELS and segmental resection remains elusive and may be impossible to perform [13]. In 2009, two relatively large series were published outlining colonic CELS outcomes [14,15]. Wilhelm et al. demonstrated that CELS performed on 146 patients gave a successful resection in $82 \%$. A total of 17 of the polyps removed were found to be carcinomas (11\%). A formal resection was required in $18 \%$ of the cases [13]. Another study by Franklin et al., reporting 160 patients, showed a successful resection margin in $91 \%$ of the cases. A total of $7 \%$ of polyps were found to be carcinoma and a formal resection was required in $14 \%$ of the cases [14]. Smaller series have reported their respective outcomes varying from a resection rate of $26-91 \%$, with a formal resection required in 9-32\% [16-19]. Our own centers have also published data in the field. Whereas a randomized comparative study is not available, a comparative study was performed by J Yoo (Ronald Reagan UCLA Medical Center, CA, USA). Outcomes for five patients having CELS procedure were compared with that of nine having resection. All patients had successful resection. No conversions in the CELS group were required. No complications occurred in the CELS group, whereas the resection group had two patients having a postoperative wound infection as well as one case of ileus. On follow-up colonoscopy, two patients exhibited residual polyp and two patients had new polyps in different locations [20]. Lee et al. recently published long-term CELS results [21]. A total of 65 patients underwent the CELS procedure with $74 \%$ of the interventions classed as successful. Importantly, both studies identified a significantly reduced in-patient stay with CELS, at 1 day, compared with resections (circa 5 days).

\section{References}

1 Zauber AG, Winawer SJ, O'Brien MJ et al. Colonoscopic polypectomy and long-term prevention of colorectal-cancer deaths. N. Engl. J. Med. 366(8), 687-696 (2012).

2 Widdison AL, Longstaff AJ, Armstrong CP. Combined laparoscopic and endoscopic treatment of gallstones and bile duct stones: a prospective study. Br. J. Surg. 81(4), 595-597 (1994)

3 Karanfilian RG, Yang HK, Gendler S. Resection of Dieulafoy's lesion by a combined

\section{- Potential benefits/complications}

Reducing the need for a colonic resection is the most fascinating potential benefit, along with obviating the complications and costs this method potentiates. Other benefits include the costs to the institution and the patient, although a formal cost analysis has not been performed to date. As data have demonstrated, length of stay is significantly reduced using the CELS technique compared with segmental resection. These cost benefits may be tempered by the requirement of having two skilled operators performing one surgery.

Surgery-specific complications, as with any laparoscopic procedure, include trocar injury, bleeding, infection and incisional hernias. Possible need for a repeat procedure pending histology is an unwanted consequence; however, from published series the number of polyps removed containing carcinomatous disease is small [14-19].

\section{Recommendation}

The vast majority of studies in the field, including the authors' own early experience, have concluded that CELS should be offered to a select subgroup of patients with favorable characteristics. We now envisage that with continuing development of tools, techniques and expertise, CELS can and should eventually be offered to all patients with polyps nonamenable to simple endoscopic polypectomy.

\section{Financial \& competing interests disclosure}

The work was supported by a NIH grant KO8DK085136 to

J Yoo. JW Milsom was a consultant for Olympus. The authors

have no other relevant affiliations or financial involvement with any organization or entity with a financial interest in or financial conflict with the subject matter or materials discussed in the manuscript apart from those disclosed.

No writing assistance was utilized in the production of this manuscript.

endoscopic and laparoscopic approach. J. Laparoendosc. Surg. 6(5), 345-348 (1996).

Ronsky J, Brody F, Matthews BD, Heniford BT. Combined endoscopic/ laparoscopic intragastric resection of gastric stromal tumors. J. Gastrointest. Surg. 7(3), 386-392 (2003).

Woodward TA, Heckman MG, Cleveland P, De Melo S, Raimondo M, Wallace M.

Predictors of complete endoscopic mucosal resection of flat and depressed gastrointestinal neoplasia of the colon. Am. J. Gastroenterol. 107(5), 650-654 (2012).
6 Moss A, Bourke MJ, Williams SJ et al. Endoscopic mucosal resection outcomes and prediction of submucosal cancer from advanced colonic mucosal neoplasia. Gastroenterology 140(7), 1909-1918 (2011).

7 Chandrasekhara V, Ginsberg GG. Endoscopic management of large sessile colonic polyps: getting the low down from down under. Gastroenterology 140(7), 1867-1871 (2011)

8 Saito Y, Uraoka T, Yamaguchi Y et al. A prospective, multicenter study of 1111 colorectal endoscopic submucosal dissections 
(with video). Gastrointest. Endosc. 72(6), 1217-1225 (2010).

9 Saito Y, Fukuzawa M, Matsuda T et al. Clinical outcome of endoscopic submucosal dissection versus endoscopic mucosal resection of large colorectal tumors as determined by curative resection. Surg. Endosc. 24(2), 343-352 (2010).

10 Nakajima K, Lee SW, Sonoda T, Milsom JW. Intraoperative carbon dioxide colonoscopy: a safe insufflation alternative for locating colonic lesions during laparoscopic surgery. Surg. Endosc. 19(3), 321-325 (2005).

11 Saltzman HA, Sieker HO. Intestinal response to changing gaseous environments: normobaric and hyperbaric observations. Ann. NY Acad. Sci. 150(1), 31-39 (1968).

12 Garrett KA, Lee SW. The evolution of minimally invasive colorectal surgery combined endoscopic-laparoscopic approaches. Semin. Colon Rectal Surg. 24(1), 32-35 (2013).

13 Wilhelm D, von Delius S, Weber L et al. Combined laparoscopic-endoscopic resections of colorectal polyps: 10 -year experience and follow-up. Surg. Endosc. 23(4), 688-693 (2009).

14 Franklin ME Jr, Portillo G. Laparoscopic monitored colonoscopic polypectomy: long-term follow-up. World J. Surg. 33(6), 1306-1309 (2009).

15 Wood JJ, Lord AC, Wheeler JM, Borley NR. Laparo-endoscopic resection for extensive and inaccessible colorectal polyps: a feasible and safe procedure. Ann. R. Coll. Surg. Engl. 93(3), 241-245 (2011).

16 Grunhagen DJ, van Ierland MC, Doornebosch PG, Bruijninckx MM, Winograd R, de Graaf EJ. Laparoscopicmonitored colonoscopic polypectomy: a multimodality method to avoid segmental colon resection. Colorect. Dis. 13(11), 1280-1284 (2011).

17 Agrawal D, Chak A, Champagne BJ, Marks JM, Delaney CP. Endoscopic mucosal resection with full-thickness closure for difficult polyps: a prospective clinical trial. Gastroint. Endosc. 71(6), 1082-1088 (2010).
18 Yan J, Trencheva K, Lee SW, Sonoda T, Shukla P, Milsom JW. Treatment for right colon polyps not removable using standard colonoscopy: combined laparoscopiccolonoscopic approach. Dis. Colon Rectum 54(6), 753-758 (2011).

19 Lee MK, Chen F, Esrailian E et al. Combined endoscopic and laparoscopic surgery may be an alternative to bowel resection for the management of colon polyps not removable by standard colonoscopy. Surg. Endosc. 27(6), 2082-2086 (2013).

20 Lee SW, Garrett KA, Shin JH, Trencheva K, Sonoda T, Milsom JW. Dynamic article: long-term outcomes of patients undergoing combined endolaparoscopic surgery for benign colon polyps. Dis. Colon Rectum 56(7), 869-873 (2013).

21 Lee SW, Garrett KA, Shin JH, Trencheva K, Sonoda T, Milsom JW. Dynamic article: long-term outcomes of patients undergoing combined endolaparoscopic surgery for benign polyps. Dis. Colon Rectum 56(7), 869-873 (2013). 